\title{
Relation between lipid polymorphism and transbilayer movement of lipids in rat liver microsomes
}

\author{
Gert van Duijn, Joost Luiken, Arie J. Verkleij and Ben de Kruijff \\ Institute of Molecular Biology and Medical Biotechnology, University of Utrecht, Padualaan 8. \\ 3584 CH Utrecht (The Netherlands)
}

(Received 31 July 1986)

Key words: Transbilayer movement; Phosphatidylcholine; Transfer protein;
Lipid polymorphism; ${ }^{31}$ P-NMR; Trinitrobenzenesulfonic acid

We have studied the effects of trinitrophenylation on the transbilayer movement of phosphatidylcholine and the macroscopic lipid structure in rat liver microsomal membranes. The transbilayer movement of phosphatidylcholine was investigated using the PC-specific transfer protein. ${ }^{31} \mathrm{P}$-NMR was employed to monitor the phospholipid organization in intact microsomal vesicles. The results indicate that modification of microsomes with trinitrobenzenesulfonic acid enhances the transbilayer movement of phosphatidylcholine at $4^{\circ} \mathrm{C}$. Furthermore, phosphatidylethanolamine headgroup trinitrophenylation in microsomes increases the isotropic component in the ${ }^{31} \mathrm{P}$-NMR spectra even at $4^{\circ} \mathrm{C}$, possibly representing the appearance of intermediate non-bilayer lipid structures. The observed parallel between these data suggests that phosphatidylethanolamine molecules in the microsomal membrane, probably in combination with a protein component, are able to destabilize the bilayer organization, thereby facilitating the transmembrane movement of phospholipids.

\section{Introduction}

The topology of biosynthesis [1] and the asymmetric transverse distribution of phospholipids in rat liver endoplasmic reticulum as inferred from experiments on isolated microsomes [2] require a mechanism for the translocation of these lipids across the membrane. In microsomes the transbi-

\footnotetext{
Abbreviations: PC, phosphatidylcholine; PE, phosphatidylethanolamine; PS, phosphatidylserine; PI, phosphatidylinositol; $\mathrm{diC}_{4} \mathrm{PC}, s n$-1,2-dibutyroylphosphatidylcholine; TNPPE, trinitrophenylphosphatidylethanolamine; TNBS, trinitrobenzenesulfonic acid; MLV, multilamellar vesicles; SUV, small unilamellar vesicles; NMR, nuclear magnetic resonance; $\Delta \sigma$, residual chemical shift anisotropy.
}

Correspondence: Dr. G. van Duijn, Institute of Molecular Biology, University of Utrecht, Padualaan 8, $3584 \mathrm{CH}$ Utrecht, The Netherlands. layer movement of phosphatidylcholine (PC) has been demonstrated previously with reported halftimes shorter than 5 [3] or $45 \mathrm{~min}$ [4] at physiological temperature. This is very rapid as compared for example to the observed half-times of PC transbilayer movement in the erythrocyte membrane [5]. More recently such a rapid transmembrane movement in microsomes also has been shown for phosphatidylethanolamines [6,7]. The mechanism by which this phospholipid transfer occurs is not known. Recently, by using the water soluble $\mathbf{L}-\boldsymbol{\alpha}$-dibutyroylphosphatidylcholine as a probe molecule, Bishop and Bell [8] have suggested that PC translocation across the microsomal membrane could be protein mediated.

Transiently formed non-lamellar lipid structures could also provide a lipid translocation mechanism (for reviews, see Refs. 9, 10). Such a mechanism is supported by the observation that 
transbilayer movement of lipids in mixed model membrane systems is increased under conditions which destabilize the lamellar organization $[11,12]$. In these mixed phospholipid model membrane systems a prerequisite for the enhanced transbilayer movement of the lipids was the presence of phospholipids which prefer on their own a hexagonal $\left(\mathrm{H}_{\|}\right)$type of structure. PE is the best studied example of a membrane phospholipid that can undergo a temperature dependent transition from bilayer to hexagonal $\left(H_{\|}\right)$phase [13,14]. Most interestingly, hydrated PE purified from rat liver microsomes organize in the hexagonal $\left(\mathrm{H}_{\|}\right)$phase above $7^{\circ} \mathrm{C}$ [17]. Although the isolated microsomal phospholipids form bilayers upon hydration [16], ${ }^{31} \mathrm{P}$-NMR data have shown that at $37^{\circ} \mathrm{C}$ a considerable portion of the phospholipids in microsomes undergoes rapid isotropic motion $[15,17,18]$. Unfortunately, isotropic ${ }^{31} \mathrm{P}-\mathrm{NMR}$ signals cannot give exclusive information about the macroscopic structure of the lipids. Although lateral diffusion of lipids around the relatively small microsomes in theory can give rise to such spectra $[19,20]$, the possibility that transiently occurring intermediate non-lamellar structures, for instance induced by microsomal proteins like e.g. cytochrome $P-450$ [18], contribute to such isotropic signals cannot be excluded. This is especially possible given the hexagonal $\left(\mathrm{H}_{\|}\right)$phase prefering character of the microsomal PE [17] and the observed specific interaction between $\mathrm{PE}$ and cytochrome $P-450$ in microsomes [21].

The aim of the study presented in this paper was to relate the macroscopic lipid structure after modification of the PE component in the membrane to the transbilayer movement of phospholipids in rat liver microsomes. Recently we described that trinitrophenylphosphatidylethanolamine shows an even stronger tendency to destabilize model membrane bilayers than the corresponding PE [16]. In addition, it has been shown that PE in intact microsomes can be modified by using TNBS [22]. Therefore we have investigated the effects of TNBS labeling on (1) the transbilayer movement of $\mathrm{PC}$ in rat liver microsomes by using the PC-specific transfer protein and (2) the macroscopic lipid structure in the microsomal membrane with ${ }^{31} \mathrm{P}-\mathrm{NMR}$. The results indicate that trinitrophenylation of $\mathrm{PE}$ in microsomes both enhances the transmembrane motion of $\mathrm{PC}$ and induces isotropic ${ }^{32} \mathrm{P}-\mathrm{NMR}$ signals, possibly reflecting the appearance of intermediate non-bilayer structures.

\section{Materials and Methods}

\section{Animals}

Adult male Wistar rats $(200-250 \mathrm{~g})$ were injected intraperitoneally with $1 \mathrm{mCi}$ of isotonic sodium [ $\left.{ }^{32} \mathrm{P}\right]$ phosphate (Amersham, UK) or 200 $\mu \mathrm{Ci}$ of $\left[\right.$ methyl $\left.-{ }^{14} \mathrm{C}\right]$ choline chloride (NEN, Boston, MA) dissolved in $150 \mathrm{mM} \mathrm{NaCl}, 10 \mathrm{mM}$ Hepes $(\mathrm{pH}=7.4) 16 \mathrm{~h}$ or $1 \mathrm{~h}$ before killing, respectively. The rats were starved during $16 \mathrm{~h}$.

\section{Preparation and analysis of microsomes}

Rat liver microsomes were isolated according to Dallner [23]. The final microsomal pellet was resuspended via mild sonication in a buffer containing $150 \mathrm{mM} \mathrm{NaCl}$ and $10 \mathrm{mM}$ Tris/HAc ( $\mathrm{pH}=7.4)$. Protein content was determined according to Peterson [24]. Total lipid extract of rat liver microsomes was obtained by the method of Folch et al. [25]. Phospholipids were separated by two-dimensional thin-layer chromatography according to Broekhuyse [26]. Phosphorus was determined by the method of Böttcher et al. [27].

\section{Incubation of microsomes with trinitrobenzene- sulfonic acid}

Microsomal suspensions $(1 \mathrm{ml}$ containing 10 $\mathrm{mg}$ of protein) were incubated with $3.0 \mathrm{mM}$ TNBS in $150 \mathrm{mM} \mathrm{NaCl}$ and $10 \mathrm{mM}$ Tris/ $\mathrm{HAc}(\mathrm{pH}=7.4)$ in a total volume of $10 \mathrm{ml}$ at $4^{\circ} \mathrm{C}$ during $2 \mathrm{~h}$. At the end of the incubation the microsomes were pelleted by centrifugation $\left(100000 \times g ; 4^{\circ} \mathrm{C} ; 60\right.$ min) and washed twice. The degree of microsomal PE labelled with TNBS was determined according to Higgins and Pigott [22]. In order to approximate the distribution of TNBS reacting with lipids and proteins respectively, the labeled microsomes were dissolved in $\mathrm{CHCl}_{3} / \mathrm{MeOH} / \mathrm{H}_{2} \mathrm{O}$ (1:2.2:1 $\mathrm{v} / \mathrm{v}$ ). A denaturated protein fraction was pelleted by centrifugation ( $20 \mathrm{~min}, 3000 \mathrm{rpm}$ in a Heraeus Christ centrifuge). Subsequently, the lipids were obtained after addition of $\mathrm{CHCl}_{3}$ and $\mathrm{H}_{2} \mathrm{O}$ according to the method of Bligh and Dyer [28]. After evaporation of the solvents, both lipid and 
protein fractions were dissolved in equal volumes of $10 \% \mathrm{SDS} / \mathrm{MeOH}(1: 1, \mathrm{v} / \mathrm{v})$. Absorbances were measured at $340 \mathrm{~nm}$. Assuming comparable molecular absorption coefficients, $57 \%$ of the reacted TNBS appeared to be associated with lipids and $43 \%$ was present in the protein fraction.

\section{Lipids and preparation of vesicles}

Egg PC was purified as described recently [29]. Trinitrophenylation of aminophospholipids in microsomal phospholipid extracts was performed according to the method of Van Duijn et al. [16]. Multilamellar vesicles were prepared by dispersing lipids, dried from $\mathrm{CHCl}_{3}$, in a buffer containing $100 \mathrm{mM} \mathrm{NaCl}$ and $10 \mathrm{mM}$ Tris/HAc (pH 7.4). For ${ }^{31} \mathrm{P}$-NMR experiments the buffer contained $25 \%{ }^{2} \mathrm{H}_{2} \mathrm{O}$. Small unilamellar vesicles were prepared by sonication of multilamellar vesicles under nitrogen at $0^{\circ} \mathrm{C}$ for $20 \mathrm{~min}$ using a Branson tip sonicator (energy output, $50 \mathrm{~W}$ ). After sonication, the dispersion was centrifuged $(35000 \times \mathrm{g}$; $30 \mathrm{~min} ; 4^{\circ} \mathrm{C}$ ) and the small unilamellar vesicles, present in the supernatant were used for the experiments.

\section{Microsomal membrane integrity}

Two tests of microsomal membrane integrity were used. First we measured the latency of glucose 6-phosphate with mannose 6-phosphate as substrate, based upon the method of Arion et al. [30]. In experiments with trinitrophenylated microsomes we determined the dextran $\left(M_{\mathrm{r}}=\right.$ $70000)$ accessible space in comparison to freshly prepared microsomes, essentially according to the procedure described previously [3].

\section{Microsomal phosphatidylcholine exchange assay}

Phosphatidylcholine specific transfer protein, purified from bovine liver [31], was stored in 50\% glycerol at $-20^{\circ} \mathrm{C}(531 \mu \mathrm{g} / \mathrm{ml})$. Transfer of $\left.{ }^{32} \mathrm{P}\right]$ phosphatidylcholine from microsomes to sonicated egg-PC vesicles was measured as described by Kamp et al. [32] with some slight modifications. ${ }^{32} \mathrm{P}$-labeled microsomes were incubated with a 10-fold excess (based upon phospholipid phosphorus) of small unilamellar vesicles composed of egg PC and $0.05 \mathrm{~mol} \% \quad\left[{ }^{3} \mathrm{H}\right]-$ cholesteryl hexadecyl ether as a non-exchangeable and non-metabolical marker in a total volume of
$2.7 \mathrm{ml}$. At the end of incubation $1 \mathrm{ml} 0.2 \mathrm{M}$ sodium acetate $/ \mathrm{HAc}\left(\mathrm{pH}=5.0 ; 4^{\circ} \mathrm{C}\right)$ was added and the microsomes were subsequently sedimented at $35000 \times g\left(20 \mathrm{~min} ; 4^{\circ} \mathrm{C}\right)$. The lipids from the supernatant, containing the small unilamellar vesicles, were extracted [28]. The extract was dried under a stream of nitrogen and dissolved in $5 \mathrm{ml}$ of Insta-Gel (Packard). The ${ }^{32} \mathrm{P} /{ }^{3} \mathrm{H}$ radioactivity ratio was determined with a Prias (PLD Tricarb Packard) liquid scintillation counter by using the external standard ratio method. The recovery of the ${ }^{3} \mathrm{H}$ marker varied between $70 \%$ and $80 \%$. These data were used to calculate the transfer of $\left[{ }^{32} \mathrm{P}\right] \mathrm{PC}$ from the microsomes to the lipid vesicles. Occasionally the specificity of the transfer protein towards PC was tested. In this control experiment different classes of phospholipids (PE, PS, PI and sphingomyelin) were added as markers towards the extracted lipids from the acceptor vesicles. After separation of the phospholipids by using two-dimensional thin layer chromatography [26] ${ }^{32} \mathrm{P}$ radioactivity was only observed in the PC spot. In addition the specific radioactivity in the different phospholipid classes, present in the ${ }^{32} \mathrm{P}$-labeled microsomes, has been determined. After subsequent lipid extraction from the microsomes, separation of the lipids, phosphorus determination and ${ }^{32} \mathrm{P}$-radioactivity counting, the ${ }^{32} \mathrm{P}$ label appeared to be distributed homogeneously over the various phospholipid classes in agreement with previous data [4]. Finally, in the absence of the transfer protein, the spontaneous transport of $\left[{ }^{32} \mathrm{P}\right] \mathrm{PC}$ from microsomes to lipid vesicles never exceeded $10 \%$ after an incubation period of $4 \mathrm{~h}$ at $4^{\circ} \mathrm{C}$ or $25^{\circ} \mathrm{C}$.

\section{Phosphatidylcholine exchange between model mem- branes}

For these experiments rats were injected intraperitoneally with a single dose $(200 \mu \mathrm{Ci})$ of [methyl $-{ }^{14} \mathrm{C}$ ]choline chloride $1 \mathrm{~h}$ prior to decapitation. The [methyl $\left.-{ }^{14} \mathrm{C}\right]$ choline label appeared to be present exclusively in the $\mathrm{PC}$ spot after extraction and subsequent separation of the microsomal lipids. The transfer of $\left[{ }^{14} \mathrm{C}\right] \mathrm{PC}$ from multilamellar vesicles was measured according to Noordam et al. [12] with some slight modifications [33].

\section{Nuclear magnetic resonance (NMR)}

Broad-band proton-decoupled ${ }^{31} \mathrm{P}-\mathrm{NMR}$ spec- 
tra of rat liver microsomes were recorded at 81 $\mathrm{MHz}$ on a Bruker WP200 spectrometer as described by Van Echteld et al. [34]. The $36.4 \mathrm{MHz}$ proton-decoupled (input power $18 \mathrm{~W}$ ) ${ }^{31} \mathrm{P}-\mathrm{NMR}$ spectra of aqueous lipid dispersions were recorded on a Bruker WH90 spectrometer as described previously [29]. The $0 \mathrm{ppm}$ position in the ${ }^{31} \mathrm{P}$ NMR spectra is defined by the resonance obtained from phospholipid molecules undergoing rapid $\left(\tau_{\mathrm{c}}<10^{-5} \mathrm{~s}\right)$ isotropic rotational motion in small spherical vesicles. The residual chemical shift anisotropy $(\Delta \sigma)$ of the axial symmetric powder patterns was calculated as 3 times the distance between the highfield peak and the $0 \mathrm{ppm}$ position [38]. In the $\mathrm{Mn}^{2+}$ experiments, after addition from out stock of the ion to the hydrated lipids (stepwise up to $6 \mathrm{mM}$ ), ${ }^{31} \mathrm{P}-\mathrm{NMR}$ were accumulated from subsequently two times 20000 transients with a standardized position of the sample with respect to the receiver coils. Signal intensities were determined by integration.

\section{Chemicals}

Trinitrobenzenesulfonic acid was obtained from Sigma (St. Louis, MO). Cholesteryl hexadecyl ether [cholesteryl-1,2- ${ }^{3} \mathrm{H}(\mathrm{N})$ ] (spec. act. 46.8 $\mathrm{mCi} / \mathrm{mmol}$ ) and dextran-carboxyl [carboxyl- ${ }^{14} \mathrm{C}$ ] (spec. act. $1.24 \mathrm{mCi} / \mathrm{g} ; M_{\mathrm{r}}=70000$ ) were purchased from NEN Research Products (Boston, MA.). Phosphatidylcholine transfer protein was a gift of Prof. Dr. K.W.A. Wirtz. Chloroform and methanol were distilled before use. Other reagents were of analytical grade.

\section{Results}

Microsomal phospholipid composition and membrane integrity

In liver microsomes, obtained from rats injected with a single dose of $\left[{ }^{32} \mathrm{P}\right]$ phosphate $16 \mathrm{~h}$. before decapitation, the ${ }^{32} \mathrm{P}$-label is incorporated homogeneously in the various phospholipid classes, since after chromatographic separation the phospholipid distribution patterns, determined by phosphorus measurements and ${ }^{32} \mathrm{P}$-radioactivity counting, respectively, are very similar and in agreement with previous data [36] (PC:62\%[65\%]; PE:22\%[22\%]; PS:10\%[8\%]; PI:3\%[2\%] and sphingomyelin: 3\% [3\%]; the values between brackets represent the ${ }^{32} \mathrm{P}$ distribution). When the microsomes were incubated with $3.0 \mathrm{mM}$ TNBS during $2 \mathrm{~h}\left(4^{\circ} \mathrm{C}\right), 43 \%$ of the PE fraction could be converted to TNPPE, in agreement with previous data [22].

In addition we tested the microsomal membrane integrity by measuring the glucose-6-phosphatase activity towards glucose 6-phosphate and mannose 6-phosphate. In freshly prepared microsomes the latency of enzyme activity for mannose 6-phosphate appeared to be $90 \%$, indicative for intact and right side out oriented microsomal vesicles [30]. Unfortunately, after trinitrophenylation of the microsomes the absolute glucose-6phosphatase activity decreased dramatically even for glucose 6-phosphate as a substrate. Therefore we also determined the permeability of the microsomal membrane to a macromolecule such as dextran. In a freshly prepared fraction (approx. $10 \mathrm{mg}$ protein $/ \mathrm{ml}$ ) the microsomes took up $20 \%$ of the total suspension volume. In a parallel experiment $18 \%$ of the total microsomal suspension volume appeared to be inaccessible for $\left[{ }^{14} \mathrm{C}\right]$ dextran, most likely representing the volume occupied by the dextran-impermeable microsomes. After modification of the microsomes with TNBS, this $\left[{ }^{14} \mathrm{C}\right]-$ dextran inaccessibility slightly changed to $21 \%$, while these microsomes still represented $20 \%$ of the total suspension volume. These results indicate that trinitrophenylation of microsomes does not influence the membrane impermeability for these large $\left(M_{\mathrm{r}}=70000\right)$ molecules.

\section{Exchange of microsomal phosphatidylcholine}

Fig. 1A shows the exchange protein mediated transfer of $\left[{ }^{32} \mathrm{P}\right] \mathrm{PC}$ from rat liver microsomes to small unilamellar vesicles (egg PC) as a function of time. At $4^{\circ} \mathrm{C}$ the degree of $\mathrm{PC}$ transfer reaches a level at around $45 \%$ after $2 \mathrm{~h}$ of incubation. Raising the temperature to $10^{\circ} \mathrm{C}$ results in an increase of the exchangeable $\mathrm{PC}$ pool size. This effect is even more pronounced at $25^{\circ} \mathrm{C}$, since at this temperature all PC molecules initially present in the microsomes are exchanged by the transfer protein within $60 \mathrm{~min}$ (half-time $\approx 12 \mathrm{~min}$ ), in agreement with a previous study [3]. At $37^{\circ} \mathrm{C}$ a similar behavior has been observed (data not shown). In addition it can be seen that at $10^{\circ} \mathrm{C}$ and $25^{\circ} \mathrm{C}$ the total microsomal PC behaves as a 

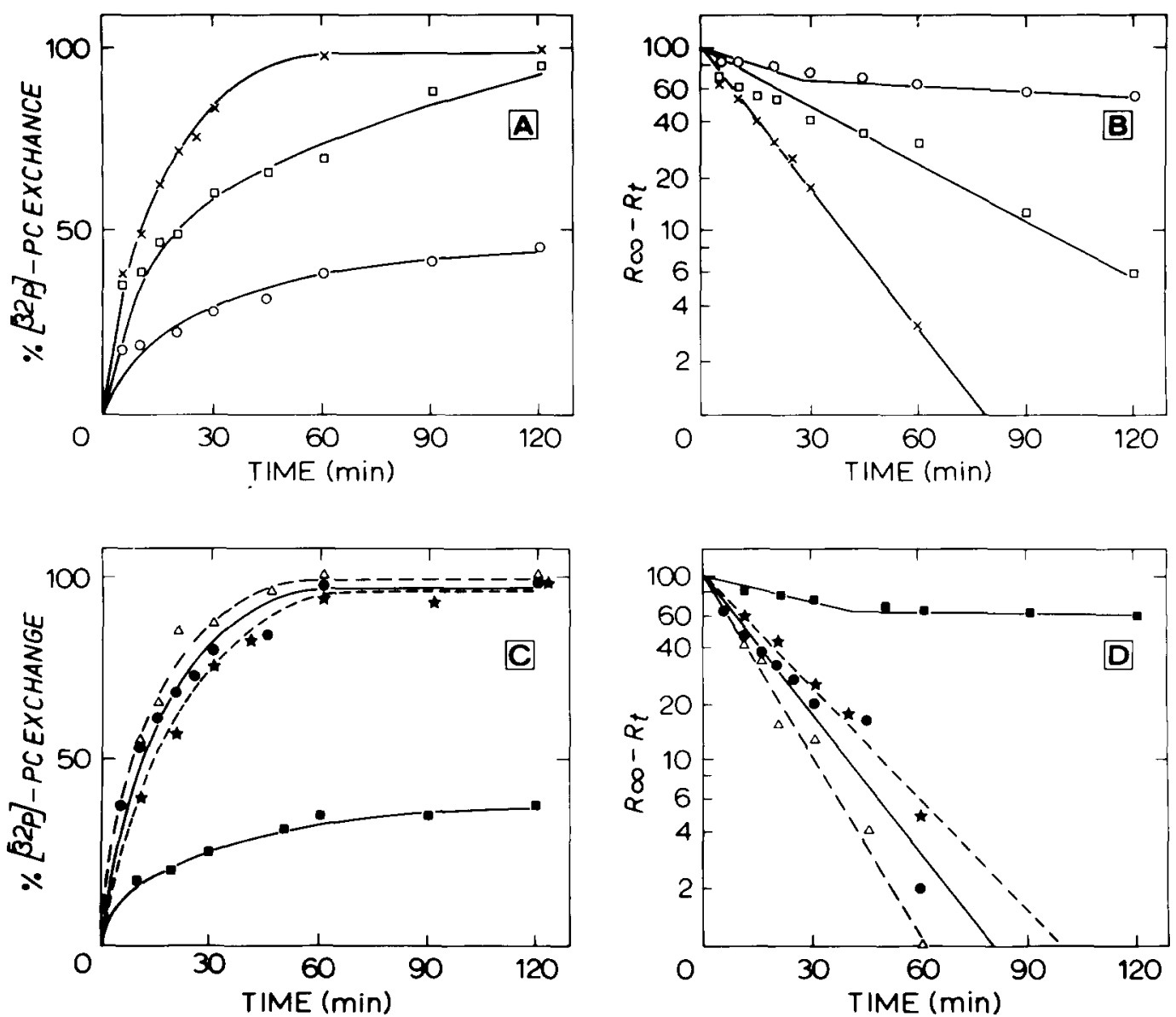

Fig. 1. Phosphatidylcholine exchange between rat liver microsomes and sonicated egg phosphatidylcholine vesicles. Aliquots of microsomes containing $400 \mathrm{nmol} \mathrm{PC}$ were incubated with SUV (4800 nmol egg PC). (A) Transfer of [ $\left.{ }^{32} \mathrm{P}\right] \mathrm{PC}$ from microsomes to SUV composed of egg PC. $\mathrm{O}$, incubation at $4^{\circ} \mathrm{C}$ with $80 \mu \mathrm{g}$ of exchange protein; $\square$, incubation at $10^{\circ} \mathrm{C}$ with $53 \mu \mathrm{g}$ of exchange protein; $\times$, incubation at $25^{\circ} \mathrm{C}$ with $22 \mu \mathrm{g}$ of exchange protein. (B) Semilogarithmic plot of data shown in (A). $R$, represents the percentage of $\left[{ }^{32} \mathrm{P}\right] \mathrm{PC}$ transfer to the SUV. $R_{\infty}$ represents $\left[{ }^{32} \mathrm{P}\right] \mathrm{PC}$ transfer at equilibrium, assuming that only the outer monolayer of the SUV and the total microsomal PC pool are available for exchange. (C) Transfer of $\left[{ }^{32} \mathrm{P}\right] \mathrm{PC}$ from trinitrophenylated microsomes to SUV at $4^{\circ} \mathrm{C}(\star)$ in the presence of $80 \mu \mathrm{g}$ of exchange protein and at $25^{\circ} \mathrm{C}(\Delta)$ in the presence of $22 \mu \mathrm{g}$ of the exchange protein. Control experiments (in the absence of TNBS) at $4^{\circ} \mathrm{C}$ (a) and $25^{\circ} \mathrm{C}(\bullet)$, respectively, with comparable amounts of exchange protein. (D) Semilogarithmic plot of data represented in (C).

single pool in the exchange process, resulting in a straight line in a plot of $\log \left(R_{\infty}-R_{t}\right)$ versus time (Fig. 1B). $R_{\mathrm{t}}$ represents the percentage of $\left[{ }^{32} \mathrm{P}\right] \mathrm{PC}$ transfer to the SUV. $R_{\infty}$ represents $\left[{ }^{32} \mathrm{P}\right] \mathrm{PC}$ transfer at equilibrium, assuming that only the outer monolayer of the SUV and the total microsomal PC pool are available for exchange. Assuming that originally the $\left[{ }^{32} \mathrm{PJPC}\right.$ is present in both the cytoplasmic and luminal leaflet of the microsomal membrane, it could be concluded that at temperatures of $10^{\circ} \mathrm{C}$ or higher these molecules move rapidly across the bilayer. At $4^{\circ} \mathrm{C}$ a more complicated PC transfer profile is observed. Since the exchange of $\left[{ }^{32} \mathrm{P}\right] \mathrm{PC}$ from microsomes did not exceed $50 \%$ within a time period of $2 \mathrm{~h}$ (Fig. 1A) and suggested two phase kinetics, we also tested the PC-transfer protein concentration dependency of this process at $4^{\circ} \mathrm{C}$. As can be seen in Table I, increasing amounts of PC-transfer protein proportionally decrease the incubation time in which 30-36\% of the total PC pool can be exchanged. However, the residual microsomal PC can be 
TABLE I

EXCHANGEABILITY OF $\left[{ }^{32} \mathrm{P}\right] \mathrm{PC}$ FROM MICROSOMES AT $4^{\circ} \mathrm{C}$

Biphasic PC exchange process as a function of PC-transfer protein (PC-TP) concentration.

\begin{tabular}{llll}
\hline $\begin{array}{l}\text { PC-TP } \\
(\mu \mathrm{g})\end{array}$ & $\begin{array}{l}\text { Rapidly exchangeable } \\
\text { pool }\end{array}$ & $\begin{array}{l}\text { Half-time }(\mathrm{h}) \text { of } \\
\text { exchange of residual } \\
\text { PC pool }\end{array}$ \\
\cline { 2 - 4 } & $\begin{array}{l}\text { size } \\
(\text { \% })^{\text {a }}\end{array}$ & $\begin{array}{l}\text { time } \\
(\mathrm{min})\end{array}$ & \\
\hline 37 & 30 & 90 & 6 \\
53 & 33 & 54 & $5-6$ \\
80 & 36 & 45 & $5-7$ \\
\hline
\end{tabular}

a The rapid exchangeable pool size is determined by the kink in the semi-logarithmic plots representing exchange versus time.

transferred only very slowly with half times ranging between 5 and $7 \mathrm{~h}$, independent of the PC transfer protein concentration (Table I). These results further support the interpretation that at $4^{\circ} \mathrm{C}$ a biphasic PC exchange process occurs (Fig. 1B). The rapid exchangeable pool most likely represents the PC molecules available for exchange in the outer monolayer of the microsomal vesicles. In agreement with previous data [3], the limited exchangeability of the second PC pool is probably reflecting the slow $\mathrm{PC}$ transbilayer movement.

Trinitrophenylation of rat liver microsomes drastically influences the rapidly exchangeable PC pool size at $4^{\circ} \mathrm{C}$. As can be seen in Fig. $1 \mathrm{C}$ and $1 \mathrm{D}$, respectively, nearly $100 \%$ of the microsomal
$\mathrm{PC}$ is available for transfer protein mediated exchange as a single pool at this temperature within $90 \mathrm{~min}$ (half-time $\approx 14 \mathrm{~min}$ ). In the control experiment at $4^{\circ} \mathrm{C}$, including a preincubation of $2 \mathrm{~h}$, in the absence of TNBS, only $38 \%$ of the total amount of PC can be transferred from the microsomes to the acceptor vesicles within $120 \mathrm{~min}$. These results strongly suggest that modification of microsomes with TNBS greatly facilitates the PC transbilayer movement at $4^{\circ} \mathrm{C}$. At $25^{\circ} \mathrm{C}$, where the rate of exchange is solely determined by the kinetics of the transfer protein catalyzed exchange reaction, trinitrophenylation hardly further stimulates the exchangeability of microsomal PC (Fig. $1 \mathrm{C}$ and $1 \mathrm{D})$.

\section{${ }^{31} P$-NMR of rat liver microsomes}

In order to relate trinitrophenylation induced PC transbilayer movement with possible structural changes in the microsomal membrane we performed ${ }^{31} \mathrm{P}-\mathrm{NMR}$ experiments. Fig. $2 \mathrm{~A}$ shows the ${ }^{31}$ P-NMR spectra obtained from microsomes at various temperatures. At $4^{\circ} \mathrm{C}$ nearly all microsomal phospholipids give rise to an axially symmetric powder pattern typical for phospholipids undergoing long-axis rotation in a bilayer organization [35]. The characteristic low-field shoulder and high-field peak are separated by approximately $27 \mathrm{ppm}$. At this temperature only a very limited fraction of the phospholipid molecules undergoes rapid isotropic motion, as indicated by the small peak at $0 \mathrm{ppm}$. In addition, probably some free moving phosphorus containing small $4^{\circ} \mathrm{C}$
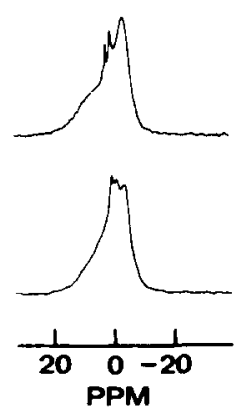

$10^{\circ} \mathrm{C}$
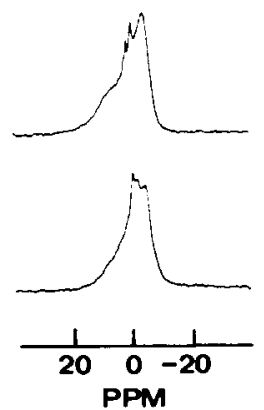

$25^{\circ} \mathrm{C}$
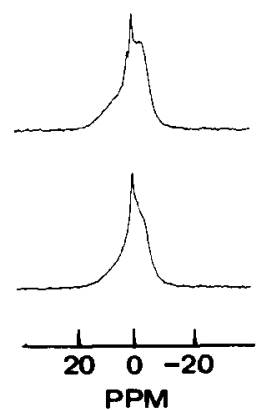

$37^{\circ} \mathrm{C}$

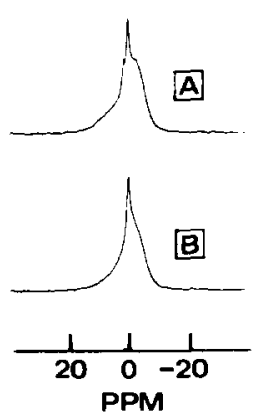

Fig. 2. Proton-decoupled $81.0 \mathrm{MHz}{ }^{31} \mathrm{P}-\mathrm{NMR}$ spectra of rat liver microsomes (A) and trinitrophenylated microsomes (B), recorded at $4^{\circ} \mathrm{C}, 10^{\circ} \mathrm{C}, 25^{\circ} \mathrm{C}$ and $37^{\circ} \mathrm{C}$, respectively. 


\section{TABLE II}

${ }^{31} \mathrm{P}$-NMR RESIDUAL CHEMICAL SHIFT ANISOTROPIES

$\Delta \sigma(\mathrm{ppm})$ is defined by 3 -times the distance between the high-field peak and the $0 \mathrm{ppm}$ position of the axial symmetric

${ }^{31} \mathrm{P}$-NMR powder patterns.

\begin{tabular}{lllll}
\hline & $4^{\circ} \mathrm{C}$ & $10^{\circ} \mathrm{C}$ & $25^{\circ} \mathrm{C}$ & $37^{\circ} \mathrm{C}$ \\
\hline Microsomes & 27 & 24.9 & 16.5 & 14.7 \\
$\begin{array}{l}\text { Trinitro- } \\
\text { phenylated }\end{array}$ & 24 & 23.4 & & \\
$\begin{array}{l}\text { microsomes } \\
\text { MLV composed }\end{array}$ & 10.5 & 10.2 & & \\
$\begin{array}{l}\text { of trinitrophenylated } \\
\text { microsomal phospholipids }\end{array}$ & 36.5 & & & \\
\hline
\end{tabular}

a,b Data are presented for both the broad and narrow spectral components.

b Data obtained from Ref. 16.

molecules are present in this microsomal sample, resulting in a peak in the ${ }^{31} \mathrm{P}-\mathrm{NMR}$ spectrum at 3 $\mathrm{ppm}$. With increasing the temperature two effects can be observed in the spectrum. First, the residual chemical shift anisotropy, defined by the distance between the low-field shoulder and the high-field peak, decreases (Table II). Second, the isotropic component in the spectra starts to dominate at higher temperatures (Fig. 2A).

After trinitrophenylation of the microsomes similar types of spectral changes can be seen. However, as shown in Fig. 2B and Table II, these effects are not exclusively due to changes in temperature, but are also the direct result of the interaction of TNBS with the microsomal membrane. As an example, at $4^{\circ} \mathrm{C}$ the isotropic component in the ${ }^{31} \mathrm{P}-\mathrm{NMR}$ spectrum of trinitrophenylated microsomes shows a higher intensity as compared to that of non-modified microsomes. Also at higher temperatures the intensity of the isotropic ${ }^{31} \mathrm{P}-\mathrm{NMR}$ signal derived of trinitrophenylated microsomes exceeds that obtained from non-labeled microsomes. Furthermore, as can be measured both at $4^{\circ} \mathrm{C}$ and $10^{\circ} \mathrm{C}$, the residual chemical shift anisotropy reduces as a result of TNBS labeling (Table II). Besides the elimination of the resonance at $3 \mathrm{ppm}$, representing the loss of free moving phosphorus containing small molecules, probably due to washing procedures, at $4^{\circ} \mathrm{C}$ a new resonance intensity appears in the spectrum at $-3.5 \mathrm{ppm}$. Recently we have shown that TNPPE itself, when incorporated in mixed phospholipid bilayers gives rise to an axially symmetric ${ }^{31} \mathrm{P}-\mathrm{NMR}$ powder pattern with a reduced $\Delta \sigma$ of 17 ppm [16], due to a different headgroup conformation of TNPPE as compared to the natural phospholipids $(\Delta \sigma \approx 40 \mathrm{ppm})$. Since the broad ${ }^{31} \mathrm{P}$ NMR bilayer component of the trinitrophenylated microsomes at $4^{\circ} \mathrm{C}$ shows a reduced $\Delta \sigma(24 \mathrm{ppm})$ as compared to that observed for model membrane bilayers (Table II), this new resonance intensity at -3.5 ppm could represent the high-field peak of an axially symmetric powder pattern derived of TNPPE with a proportionally reduced $\Delta \sigma$ of $10.5 \mathrm{ppm}$.

\section{${ }^{31} P$-NMR of microsomal lipid systems}

Recently we presented ${ }^{31} \mathrm{P}-\mathrm{NMR}$ data concerning the effects of TNPPE on the macroscopic structure of hydrated lipids derived from rat liver microsomes [16]. In short, in the control experiment in the absence of TNPPE, all microsomal phospholipids appear to organize in bilayers up till $70^{\circ} \mathrm{C}$. After trinitrophenylation of the aminophospholipid headgroups in organic solvent, the hydrated microsomal lipids show a drastically changed temperature dependent phase behavior, represented by sharp isotropic ${ }^{31} \mathrm{P}-\mathrm{NMR}$ signals at $70^{\circ} \mathrm{C}$ and a pronounced hysteresis after subsequent cooling, indicative for a stable macroscopic reorganization of the previous bilayer structure.

We confirmed these data and studied, in addition, the effect of $\mathrm{Mn}^{2+}$ on the ${ }^{31} \mathrm{P}-\mathrm{NMR}$ characteristics. This paramagnetic ion will broaden the resonances of those lipid molecules which can be approached closely, i.c. in the absence of $\mathrm{Mn}^{2+}$ permeability and lipid transbilayer movement, those molecules present in the outer monolayer. Under the experimental conditions we used, including $83 \mu \mathrm{s}$ delay between pulse and start of data acquisition, the broadened ${ }^{31} \mathrm{P}-\mathrm{NMR}$ resonances can not be detected anymore. The resulting residual signal intensities give information about the portion of phospholipids present in the outer monolayer of the liposomal system. After addition of up to $6 \mathrm{mM} \mathrm{Mn^{2+ }}$ to hydrated microsomal phospholipid systems, the ${ }^{31} \mathrm{P}-\mathrm{NMR}$ spectrum reduces in signal intensity to a stable value of $70 \%$ at $25^{\circ} \mathrm{C}$. After heat-treatment $\left(70^{\circ} \mathrm{C} ; 1 \mathrm{~h}\right)$ of an 
identical lipid sample, addition of the same concentrations of the $\mathrm{Mn}^{2+}$ ion at $25^{\circ} \mathrm{C}$ results in a signal intensity which was stable for at least $2 \mathrm{~h}$. corresponding to $68 \%$ of the original value. This result indicates that in MLV comprised of microsomal phospholipids about $30 \%$ of the molecules are localized in the outer monolayer and that this number is not affected by heat-treatment. In aqueous microsomal phospholipid systems in which the aminophospholipids were trinitrophenylated, addition of up to $6 \mathrm{mM} \mathrm{Mn}^{2+}$ at $25^{\circ} \mathrm{C}$ results in a reduction of the ${ }^{31} \mathrm{P}-\mathrm{NMR}$ bilayer signal intensity of $22 \%$. However, after heat-treatment $\left(70^{\circ} \mathrm{C} ; 1 \mathrm{~h}\right)$ of this sample, addition of comparable concentrations of $\mathrm{Mn}^{2+}$ at $25^{\circ} \mathrm{C}$ gives rise to a complete disappearance of the ${ }^{31} \mathrm{P}-\mathrm{NMR}$ signal. This observation shows an increased permeability towards $\mathrm{Mn}^{2+}$ under conditions that the lipid bilayer structure is destabilized by the presence of TNPPE.

\section{Exchange of phosphatidylcholine in microsomal lipid model membranes}

The next objective of this study was to relate the observed bilayer destabilizing effect of TNPPE [16] and the transbilayer movement of PC in multilamellar model membrane systems. Therefore we studied the effect of trinitrophenylation on the exchangeability of PC from MLV composed of microsomal phospholipids. Fig. 3A shows the transfer of $\left[{ }^{14} \mathrm{C}\right] \mathrm{PC}$ from $\mathrm{MLV}$ in the absence of TNPPE. At $25^{\circ} \mathrm{C} 39 \%$ of the PC pool is available for exchange. After heat-treatment at $70^{\circ} \mathrm{C}$ during $1 \mathrm{~h}$ and subsequent cooling to $25^{\circ} \mathrm{C}$, thereby not effecting the macroscopic lipid structure, this number slightly increases to $44 \%$. After quantitative trinitrophenylation of the aminophospholipids, again $40 \%$ of the ${ }^{14} \mathrm{C}$-labeled $\mathrm{PC}$ molecules can be transferred from the MLV to the small unilamellar vesicles at $25^{\circ} \mathrm{C}$ (Fig. 3B). However, after heat-treatment of these $\operatorname{MLV}\left(70^{\circ} \mathrm{C} ; 1 \mathrm{~h}\right)$ the exchange protein mediated transfer of the PC molecules increased to $60 \%$. These results suggest that the combination of trinitrophenylation and heat-treatment, thereby leading to bilayer destabilization [16], enables a fraction of the total PC pool to redistribute between inner compartments and the outer monolayer of these lipid structures.

\section{Discussion}

The aim of the present study was to relate the transbilayer movement of phospholipids to the macroscopic structure of the membrane lipids in rat liver microsomes. We have shown that above $10^{\circ} \mathrm{C}$ all $\mathrm{PC}$ molecules present in the microsomal membrane are available for exchange as a single pool by using the PC specific transfer protein. This result confirms previous data and the suggestion $[3,4]$ that at these temperatures the PC molecules can undergo rapid transbilayer movement (half-time at $25^{\circ} \mathrm{C}<12 \mathrm{~min}$ ). Prerequisites for this interpretation are that the transfer protein cannot permeate the membrane nor facilitates the lipid translocation by itself, and that the ${ }^{32} \mathrm{P}$ labeled PC molecules are initially present on both sides of the microsomal membrane. The observed latency of glucose-6-phosphatase activity for mannose 6-phosphate makes a rapid permeation of the
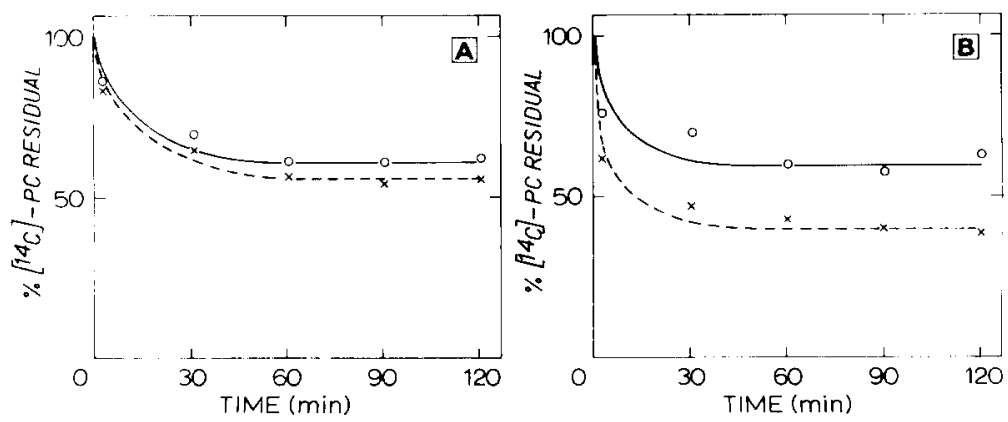

Fig. 3. Transfer protein mediated exchange of $\left[{ }^{14} \mathrm{C}\right] P C$ between MLV and SUV at $25^{\circ} \mathrm{C} \mathrm{(A)}$ and at $25^{\circ} \mathrm{C}$ after heat-treatment of the MLV at $70^{\circ} \mathrm{C}$ during $1 \mathrm{~h}$. (B) MLV were comprised of microsomal phospholipids (O) or of microsomal phospholipids of which the aminophospholipids were trinitrophenylated $(\times)$. The incubation mixtures contained MLV $(0.4 \mu$ mol phospholipid), SUV (4 $\mu$ mol egg PC and $2 \cdot 10^{5} \mathrm{dpm}\left[{ }^{3} \mathrm{H}\right]$ cholesteryl hexadecyl ether, as a non-exchangeable marker) and $10 \mu \mathrm{g}$ PC-transfer protein. 
transfer protein through the microsomal membrane most unlikely. In addition, the limited exchangeable pool size $(\approx 60 \%)$ of PC in SUV composed of microsomal phospholipids [3] indicates that the transfer protein does not induce transmembrane movement of these phospholipids by itself, although such an induction in cooperation with microsomal membrane proteins cannot be excluded. Furthermore, previous data $[2,4,37]$ assured that $\mathrm{PC}$ is present in both the cytoplasmic and luminal leaflet of the microsomal membrane and is uniformly ${ }^{32} \mathrm{P}$-labeled, $1 \mathrm{~h}$ after injection of the rat with $\left[{ }^{32} \mathrm{P}\right]$ phosphate.

Apparently, in agreement with former results [3], at $4^{\circ} \mathrm{C}$ such a rapid $\mathrm{PC}$ transbilayer movement does not occur as the protein mediated exchange process shows biphasic kinetics. The observation that only the kinetics of the rapidly exchangeable PC pole are proportionally dependent on the transfer protein concentration, strongly suggests that the slowly exchangeable PC pool represents those molecules which are initially present on the luminal face of the microsomal membrane and can not undergo rapid transbilayer movement.

The $\mathrm{PC}$ exchange characteristics at $4^{\circ} \mathrm{C}$ are dramatically influenced by trinitrophenylation of microsomes. Under conditions that $43 \%$ of the PE fraction is trinitrophenylated, all PC molecules in the microsomes behave as a single pool which is available for exchange with a half-time of $14 \mathrm{~min}$. This increased exchangeability of PC is probably not caused by changes in permeability for the transfer protein since after trinitrophenylation the microsomes retain their inaccessibility towards large molecules such as dextran. Since next to aminophospholipids also (membrane-)proteins become trinitrophenylated by TNBS it could be argued that the increased transbilayer movement of $\mathrm{PC}$ at $4^{\circ} \mathrm{C}$ is the result of an activation of a protein involved in this process. We consider this unlikely since trinitrophenylation more likely will cause a loss of enzymatic activity as we observed for instance with glucose-6-phosphatase. Recently, Bishop and Bell [8] reported a reduction of the transfer of $\mathrm{diC}_{4} \mathrm{PC}$ across the microsomal membrane as a result of TNBS modification. These authors argued that this result would be an indication for the existence of a protein transporter for PC. The use of the highly artificial short chain PC analogue in their study could cause the discrepancy with the present results. Our data suggest that the increase of the rapidly exchangeable PC pool size at $4^{\circ} \mathrm{C}$, representing the enhancement of transbilayer movement of lipids, is the result of the trinitrophenylation of the microsomal amino-phospholipids.

In order to relate these observations to possible structural changes in the microsomal membrane as a result of trinitrophenylation we performed ${ }^{31} \mathrm{P}$ NMR experiments. At $4^{\circ} \mathrm{C}$ in freshly prepared microsomes all phospholipid molecules appear to be organized in bilayers, thereby giving rise to a ${ }^{31}$ P-NMR spectrum characterized by an axial symmetric powder pattern, in agreement with published data [17]. However, the residual chemical shift anisotropy of this "bilayer" type of spectrum is small as compared to that determined for phospholipid molecules organized in multilamellar model membranes [35]. This reduction in linewidth of the microsomal ${ }^{31} \mathrm{P}$-NMR spectra becomes more dominant at higher temperatures, resulting in a further decrease in $\Delta \sigma$ and the appearance of a broad isotropic signal which dominates the spectrum at $37^{\circ} \mathrm{C}$. These spectral changes in principle can be caused by a number of different mechanisms, e.g., (1) changes in headgroup structure, (2) changes in rate of lateral movement of lipids in a curved membrane and (3) rapid changes in phospholipid orientation within the membrane. Computer simulations of ${ }^{31} \mathrm{P}-\mathrm{NMR}$ spectra of phospholipids with various types of headgroup orientations have demonstrated that the ${ }^{31}$ P-NMR lineshape and $\Delta \sigma$ are dependent on the local conformation of the headgroup [37]. However, experimental evidence obtained so far suggest that the phosphate region of naturally occurring diacyl phospholipids has a highly conserved structure in both model and biological membranes which is the reason for the fact that the ${ }^{31} \mathrm{P}-\mathrm{NMR}$ spectrum of such phospholipids in extended and planar bilayers virtually always is characterized by an axially symmetric lineshape with a $\Delta \sigma$ of around $40 \mathrm{ppm}$. Therefore it is highly unlikely that changes in headgroup structure cause the observed spectral changes. Rapid isotropic reorientation of phospholipid molecules in a curved membrane of a vesicular structure as a microsome can be the result of either vesicle tum- 
bling or lateral diffusion of the lipids within the membrane. Both theoretically [20] and experimentally [15] contributions of microsomal tumbling to the observed reduction in $\Delta \sigma$ and the change from an axially symmetric to an isotropic line shape can be excluded. In contrast lateral diffusion of lipid molecules within bilayers of microsomal vesicles which have a size range between 80 and $200 \mathrm{~nm}$ in diameter [20], can cause an averaging of the chemical shift anisotropy leading to either a reduction of $\Delta \sigma$ or, for the smallest microsomes at higher temperatures, an isotropic ${ }^{31} \mathrm{P}-\mathrm{NMR}$ lineshape $[19,20]$. Unfortunately, an exact quantification of the lateral diffusion contribution to the changes in ${ }^{31}$ P-NMR lineshape can not be given due to uncertainties in the rate of lateral diffusion of the phospholipids in the microsomal membrane and the choice of the model for lateral diffusion. Therefore, the third possibility that the peculiar ${ }^{31} \mathrm{P}-\mathrm{NMR}$ lineshapes in rat, bovine and rabbit liver microsomes $[15,17,18]$ are due to rapid changes in phospholipid orientation within the membrane, for instance due to transiently formed non-bilayer structures has to be considered. There are several arguments consistent with such a dynamic nature of the microsomal phospholipid component. Transbilayer movement of phospholipids, under equilibrium conditions (without significant turnover or net synthesis of lipids), is uniquely high. Furthermore, isolated hydrated PE, which amounts to $22 \%$ of the total phospholipid pool in microsomes shows a bilayer to hexagonal $\left(\mathrm{H}_{\|}\right)$phase transition around $7^{\circ} \mathrm{C}$ [17] and thus prefers a non-bilayer organization at higher temperatures.

In considering the effects of trinitrophenylation of the aminophospholipids in the microsomal membrane on membrane structure it is usefull to recall that trinitrophenylation of $\mathrm{PE}$ results in a stronger tendency to adopt the $\mathrm{H}_{\|}$phase, manifested by a shift in bilayer to hexagonal $\left(\mathrm{H}_{\|}\right)$ phase transition temperature towards lower values [16]. This effect is mainly due to headgroup dehydration [16]. Another result of the reaction of TNBS with PE is the strong reduction in $\Delta \sigma$ of the ${ }^{31}$ P-NMR spectrum of the trinitrophenyl derivative which most likely is due to a change in headgroup conformation [16]. In the ${ }^{31} \mathrm{P}-\mathrm{NMR}$ spectra of mixed lipid systems the TNPPE compo- nent can be readily identified as a second axially symmetric component with a strongly reduced $\Delta \sigma$. Also in the ${ }^{31} \mathrm{P}-\mathrm{NMR}$ spectra of the TNBS-treated microsomes investigated in this study a new spectral component is observed which most likely represents the high-field peak of an axially symmetric powder pattern with a $\Delta \sigma$ of $10.5 \mathrm{ppm}$. We interprete this as the ${ }^{31} \mathrm{P}-\mathrm{NMR}$ spectrum arising from TNPPE within the microsomal membrane. The slightly smaller value of $\Delta \sigma$ as compared to pure lipid systems [16] might be caused by the additional motional averaging possibilities in the microsomal membrane. The second and most pronounced changes in the overall microsomal ${ }^{31} \mathrm{P}$ NMR lineshapes upon trinitrophenylation are the shift towards lower values of $\Delta \sigma$ and the more isotropic character of the lineshapes already occurring now at lower temperatures. Since it is unlikely that these changes are caused by an increase in the rate of lateral diffusion or changes in the microsomal vesicle size [22] and trinitrophenylation promotes the formation of non-bilayer structures, we suggest that trinitrophenylation results in rapid phospholipid reorientations within the microsomal membrane already at $4^{\circ} \mathrm{C}$ for instance as a result of transient non-bilayer lipid structures, possibly of an inverted micellar nature.

Apparently, there appears to be a striking parallel between the trinitrophenylation induced transbilayer movement of $\mathrm{PC}$ and possible structural changes in the microsomal membrane. In order to further substantiate the involvement of transient non-bilayer lipid structures in functional membrane properties we studied the effect of TNPPE on the exchangeability of PC in MLV composed of microsomal phospholipids. In the absence of TNPPE, hydrated microsomal phospholipids organize in bilayers up to $70^{\circ} \mathrm{C}$ [16]. Under these conditions about $40 \%$ of the total PC pool is available for exchange within $2 \mathrm{~h}$. This number closely matches the amount of PC molecules present in the outer monolayer of these large lipid vesicles, as has been confirmed by $\mathrm{Mn}^{2+}$ titrations in ${ }^{31} \mathrm{P}-\mathrm{NMR}$ experiments. Therefore this result indicates that in these multilamellar vesicles there is no rapid transbilayer movement of PC, in agreement with previous data [3]. In contrast, as has been shown previously [16], afte trinitrophenylation of the amino-phospholipid headgroups in 
organic solvents, the hydrated microsomal phospholipids show a dramatically changed temperature dependent phase behavior. After heat-treatment at $70^{\circ} \mathrm{C}$, the lipid molecules reorganize from a bilayer structure to a phospholipid structure characterized by an isotropic ${ }^{31} \mathrm{P}-\mathrm{NMR}$ lineshape at $25^{\circ} \mathrm{C}$, possibly representing an intermediate stage between bilayer and hexagonal $\left(\mathrm{H}_{\|}\right)$phase $[10,16]$. Because this structure has very different characteristics than a conventional bilayer, we name this operationally a non-bilayer structure. In ${ }^{31} \mathrm{P}-\mathrm{NMR}$ experiments, addition of $\mathrm{Mn}^{2+}$ to this intermediate non-bilayer structures results in a complete disappearance of the signal. This result indicates that under conditions that the lipid bilayer structure is destabilized by TNPPE, either the permeability towards $\mathrm{Mn}^{2+}$ is drastically increased or the lipid molecules are able to move freely from the inner shells to the surface of the resulting structure, thereby approaching the paramagnetic ion closely. Indeed, we have shown that under otherwise similar conditions now $60 \%$ of the PC pool becomes available for exchange by the transfer protein. From these data it can be concluded that there is a direct relation between destabilization of the bilayer structure by TNPPE and the enhanced transbilayer movement of PC.

The data presented and discussed in this paper indicate that the phase behavior of PE in microsomes can be changed by headgroup trinitrophenylation reactions, which further emphasizes the temperature-dependent manner in which PE molecules in the microsomal membrane are able to (transiently) destabilize the bilayer organization. However, as has been proposed previously [18], the exclusive role of proteins like e.g. cytochrome $P-450$ in regulating the macroscopic lipid structure should not be underestimated. This is especially relevant as (1) the lipids, derived from the microsomal membrane, prefer a bilayer organization after hydration at physiological temperatures and (2) the PE component appears to interact specifically with cytochrome $P-450$ in $\mathrm{mi}-$ crosomes [21].

\section{Acknowledgment}

We thank Prof. Dr. K.W.A. Wirtz and Dr. D. van Loon for their generous gift of the transfer protein.

\section{References}

1 Bell, R.M., Ballas, L.M. and Coleman, R.A. (1981) J. Lipid Res. 22, 391-403

2 Nillson, O. and Dallner, G. (1977) J. Cell Biol. 72, 568-583

3 Van Den Besselaar, A.M.H.P., De Kruijff, B., Van den Bosch, H. and Van Deenen, L.L.M. (1978) Biochim. Biophys. Acta 510, 242-255

4 Zilversmit, D.B. and Hughes, M.E. (1977) Biochim. Biophys. Acta 469,99-110

5 Renooy, W., Van Golde, L.M.G., Zwaal, R.F.A. and Van Deenen, L.L.M. (1976) Eur. J. Biochem. 61, 53-58

6 Hutson, J.L. and Higgins, J.A. (1982) Biochim. Biophys. Acta $687,247-256$

7 Sleight, R.G. and Pagano, R.E. (1985) J. Biol. Chem. 260, 1146-115

8 Bishop, W.R. and Bell, R.M. (1985) Cell 42, 51-60

9 De Kruijff, B., Cullis, P.R., Verkleij, A.J., Hope, M.J., Van Echteld, C.J.A. and Taraschi, T.F. (1984) in The Enzymes of Biological Membranes (Martinosi, A., ed.), pp. 131-204, Plenum Press, New York

10 Verkleij, A.J. (1984) Biochim. Biophys. Acta 779, 43-63

11 Gerritsen, W.J., De Kruijff, B., Verkleij, A.J. and De Gier, J. (1980) Biochim. Biophys. Acta 598, 554-560

12 Noordam, P.C., Van Echteld, C.J.A., De Kruijff, B. and De Gier, J. (1981) Biochim. Biophys. Acta 646, 483-487

13 Cullis, P.R. and De Kruijff, B. (1978) Biochim. Biophys. Acta 513, 31-42

14 Luzzati, V., Reiss-Husson, F., Rivas, E. and Gulik-Krzywicki, T. (1966) Ann. N.Y. Acad. Sci. 137, 409-413

15 De Kruijff, B., Van den Besselaar, A.M.H.P., Cullis, P.R. van den Bosch, H. and Van Deenen, L.L.M. (1978) Biochim. Biophys. Acta 514, 1-8

16 Van Duijn, G., Dekker, J., Leunissen-Bijvelt, J., Verkleij, A.J. and De Kruijff, B. (1985) Biochemistry 24, 7640-7650

17 De Kruijff, B., Rietveld, A. and Cullis, P.R. (1980) Biochim. Biophys. Acta 600, 343-357

18 Stier, A., Finch, S.A.E. and Bösterling, B. (1978) FEBS Lett. 91, 109-112

19 Bayerl, T., Klose, G., Ruckpaul, K., Gast, K. and Möps, A. (1984) Biochim. Biophys. Acta 769, 399-403

20 Burnell, E.E., Cullis, P.R. and De Kruijff, B. (1980) Biochim. Biophys. Acta 603, 63-69

21 Bayerl, T., Klose, G., Ruckpaul, K. and Schwarze, W. (1985) Biochim. Biophys. Acta 812, 437-446

22 Higgins, J.A. and Pigott, C.A. (1982) Biochim. Biophys. Acta $693,151-158$

23 Dallner, G. (1974) Methods Enzymol. 31, 191-201

24 Peterson, G.L. (1977) Anal. Biochem. 83, 346-356

25 Folch, J., Lees, M. and Sloane-Stanley, G.H. (1957) J. Biol. Chem. 226, 497-509

26 Broekhuyse, R.M. (1969) Clin. Chim. Acta 23, 457-461

27 Böttcher, C.J.F., van Gent, C.M. and Pries, C. (1961) Anal. Chim. Acta 24, 203

28 Bligh, E.G. and Dyer, W.J. (1959) Can. J. Biochem. Physiol, 37, 911-913

29 Van Duijn, G., Verkleij, A.J. and De Kruijff, B. (1984) Biochemistry 23, 4969-4977 
30 Arion, W.J., Wallin, B.K., Carlson, P.W. and Lange, A.J. (1972) J. Biol. Chem. 247, 2558-2565

31 Westerman, J., Kamp, H.H. and Wirtz, K.W.A. (1983) Methods Enzymol. 98, 581-586

32 Kamp, H.H., Wirtz, K.W.A. and Van Deenen, L.L.M. (1973) Biochim. Biophys. Acta 318, 313-325

33 Van Duijn, G., Valtersson, C., Chojnacki, T., Verkleij, A.J., Dallner, G. and De Kruijff, B. (1986) Biochim. Biophys. Acta 861, 211-223

34 Van Echteld, C.J.A., Van Stight, R., De Kruijff, B., Leunis-
sen-Bijvelt, J., Verkleij, A.J. and De Gier, J. (1981) Biochim. Biophys. Acta 648, 287-291

35 Seelig, J. (1978) Biochim. Biophys. Acta 515, 105-140

36 Depierre, J.W. and Dallner, G. (1975) Biochim. Biophys. Acta $415,411-472$

37 Kohler, S.J. and Klein, M.P. (1977) Biochemistry 16, $519-526$

38 McLaughlin, A.C., Cullis, P.R., Berden, J.A. and Richards, R.E. (1975) J. Magn. Resonance 20, 145-165 